OPEN ACCESS

Edited by:

Gaetano Santulli,

Columbia University, United States

Reviewed by:

Lydia Pecker,

Johns Hopkins University School of

Medicine, United States

Stephanie Howe Guarino,

Christiana Care Health System,

United States

*Correspondence:

Christophe Delclaux

christophe.delclaux@aphp.fr

Specialty section:

This article was submitted to

Clinical and Translational Physiology,

a section of the journal

Frontiers in Physiology

Received: 04 November 2019 Accepted: 15 January 2020

Published: 26 February 2020

Citation:

Bokov P, El Jurdi H, Denjoy I, Peiffer C, Medjahdi N, Holvoet L, Benkerrou M and Delclaux C (2020) Salbutamol Worsens the Autonomic

Nervous System Dysfunction of Children With Sickle Cell Disease.

Front. Physiol. 11:31

doi: 10.3389/fphys.2020.00031

\section{Salbutamol Worsens the Autonomic Nervous System Dysfunction of Children With Sickle Cell Disease}

\author{
Plamen Bokov 1,2 , Houmam El Jurdi', Isabelle Denjoy ${ }^{1}$, Claudine Peiffer', \\ Noria Medjahdi', Laurent Holvoet ${ }^{3}$, Malika Benkerrou ${ }^{3}$ and Christophe Delclaux ${ }^{1,2 *}$ \\ ${ }^{1}$ Service de Physiologie Pédiatrique, AP-HP, Hôpital Robert Debré, Paris, France, ${ }^{2}$ UMR 1141, Equipe NeoPhen, INSERM \\ co-tutelle, Université de Paris, Paris, France, ${ }^{3}$ Service d'Hématologie Pédiatrique, AP-HP, Hôpital Robert Debré, Paris, \\ France
}

Background: Sickle cell disease (SCD) patients with asthma have an increased rate of vaso-occlusive crisis (VOC) and acute chest syndrome (ACS) episodes when compared to those without asthma. We hypothesized that either asthma diagnosis or bronchodilator treatment might aggravate SCD via their modulating effect on the autonomic nervous system (ANS).

Methods: Cross-sectional evaluation of heart rate variability (HRV) during pulmonary function tests, including salbutamol administration, in children with SCD receiving asthma treatment or not when compared to asthmatic children without SCD matched for ethnicity.

Results: SCD children with asthma ( $n=30$, median age of 12.9 years old) were characterized by a reduced $\mathrm{FEV}_{1} / \mathrm{FVC}$ ratio, an increased bronchodilator response, and a greater incidence of VOC and ACS when compared to SCD children without asthma ( $n=30,12.7$ years). Children with asthma without SCD $(n=29,11.4$ years) were characterized by a higher exhaled NO fraction than SCD children. SCD children when compared to non-SCD children showed reduced HRV [total power, low (LF) and high (HF, vagal tone) frequencies], which was further worsened by salbutamol administration in all the groups: reduction in total power and HF with an increase in LF/HF ratio. After salbutamol, the LF/HF ratio of the SCD children was higher than that of the non-SCD children. The two groups of SCD children were similar, suggesting that asthma diagnosis per se did not modify ANS functions.

Conclusion: SCD children are characterized by impaired parasympathetic control and sympathetic overactivity that is worsened by salbutamol administration.

Clinical Trial Registration: www.ClinicalTrials.gov, identifier NCT04062409.

Keywords: sickle cell disease, asthma, salbutamol, heart rate variability, sympathetic activity, vagal activity, vasoocclusive event 


\section{INTRODUCTION}

Asthma diagnosis in sickle cell disease (SCD) patients is associated with worse prognosis, i.e., increased morbidity and mortality (Glassberg et al., 2014). As stated by Mehari and Klings, one of the difficulties in diagnosing asthma in SCD stems from the overlap of clinical features, which may be solely due to SCD and those of asthma in the non-SCD population (Mehari and Klings, 2016). The use of beta 2 -agonists in children with SCD and asthma confounds interpretation of whether asthma or asthma treatment is associated with worse SCD as measured by incident acute chest syndrome (ACS) and vasoocclusive crisis (VOC). For instance, in the study by Glassberg et al., including 74 SCD children, painful episodes with adequate documentation of respiratory symptoms were more frequently preceded by respiratory symptoms in the group with asthma when compared with those without asthma (Glassberg et al., 2006). One may hypothesize that these respiratory symptoms led to the intensification of bronchodilator intake that may further precipitate VOC. Similarly, in the study by Sylvester et al. (2007) more of the children who had an ACS compared to those who did not were taking anti-asthma medication.

Our working hypothesis is that beta 2 -agonists may aggravate SCD via their modulating effect on the autonomic nervous system (ANS). The few studies that have investigated ANS functions in patients with SCD have reported alterations such as decreased parasympathetic activity and sympathetic activity predominance in steady-state condition (Romero Mestre et al., 1997; Pearson et al., 2005). Furthermore, ANS dysfunction seems to be a marker of severity in SCD (Nebor et al., 2011). Beta 2 agonists may further modify ANS balance. Acute salbutamol administration increases sympathetic activity in both healthy and asthmatic subjects (Eryonucu et al., 2001; Edgell et al., 2016). As a consequence, one may hypothesize that beta 2 -agonists may aggravate ANS dysfunction of SCD that is already characterized by enhanced sympathetic activity when compared to its effect in asthmatic patients who exhibit on the opposite an enhanced parasympathetic activity (Garrard et al., 1992).

Thus, our objectives were to assess ANS functions based on heart rate variability (HRV) in patients with SCD receiving asthma treatment or not, when compared to asthmatic children without SCD, who were matched for ethnicity since its influences HRV (Hill et al., 2015), and to assess the effect of salbutamol administration on ANS in these three groups of children.

\section{MATERIALS AND METHODS}

This cross-sectional case (SCD)-control (non-SCD) study complied with STROBE guidelines.

\section{Patients}

Subjects of Sub-Saharan African or Caribbean ethnicity who were 8 to 16 years of age and were referred to the Pulmonary Function Testing Unit for the follow-up of their disease were enrolled between January 2018 and April 2019. Three groups were constituted according to the presence of asthma treatment [either on-demand (salbutamol) or continuous (inhaled corticosteroid or bronchodilator with inhaled corticosteroid or leukotriene receptor antagonist)] and SCD: SCD children without asthma treatment, SCD children with asthma treatment, and asthmatic children without SCD. For the latter group, the children had to satisfy the GINA criteria of asthma (diagnosis of asthma made by one of the hospital pediatric pulmonologist plus reversible airflow limitation in the past pulmonary function tests in the unit). Since multiple phenotypes of asthma may exist in SCD (at least asthmalike symptoms and typical asthma), all the patients underwent exhaled nitric oxide (NO), characterizing atopy (Mahut et al., 2009). SCD children were characterized as previously described, thanks to a database as part of standard patient management, VOC was defined as severe enough to require hospitalization, and ACS was defined as new pulmonary infiltrate with pain, fever, and/or hypoxemia (Sommet et al., 2016). One physician (HEJ) served as chart abstractor. An additional inclusion criterion for all children receiving anti-asthma treatment was the withdrawal of the beta-agonist before lung function tests (short-acting beta $_{2}$-agonist $>4 \mathrm{~h}$ and long-acting beta 2 -agonist $>15 \mathrm{~h}$ ). The sole exclusion criterion was the failure of the HRV analysis. This study was approved by an Ethics Committee (CPP SUDEST II, 2017-17-AM1) and the database of collected data was declared to the French regulatory agency (CNIL). The subjects and their parents gave their informed consent. The Assistance Publique-Hôpitaux de Paris (DRCI) was the sponsor of the study (DrepaSympa study-K170302).

\section{Pulmonary Function Tests and HRV Analysis}

The children/adolescents underwent functional tests, between 9:30 and 12:30 am (no acute consumption of food or water), in the following order:

- ECG recorded connection;

- Two static volume measurements using a dilution technique (normal breathing frequency: respiratory rate of $20-25 / \mathrm{min}$ ): $5 \mathrm{~min}$ for each recording. These two measurements allowed the calculation of the static volumes as recommended (Wanger et al., 2005);

- One functional residual capacity (FRC) measurement using a dilution technique with slow-paced breathing recording at six cycles per minute [ $5 \mathrm{~s}$ of inspiration, $5 \mathrm{~s}$ of expiration: 5 min as previously described (Garcia-Araújo et al., 2015)] in order to study respiratory sinus arrhythmia (RSA) that is recognized as a physiological mechanism to ensure optimal ventilation-perfusion matching within the lungs (Hayano and Yuda, 2019);

- Exhaled NO measurement at multiple flow rates to calculate alveolar $\mathrm{NO}$ concentration $\left(\mathrm{C}_{\text {alv,NO}}\right)$ and maximal bronchial NO flux ( ${ }^{\prime}$ aw,NO) as previously described (Mahut et al., 2004). J' aw,NO has been correlated to both subepithelial eosinophilic infiltration and reticular basement membrane thickness, two asthma characteristics (Mahut et al., 2004). FENO $_{0.05}$ was also given since the modeling failure of the exhaled $\mathrm{NO}$ can be observed (Mahut et al., 2006); 
- Baseline spirometry, accordingly to recommendations (Miller et al., 2005);

- DLCO/DLNO measurement to calculate the membrane diffusion (DM) and capillary blood volume (VC), as recommended (Zavorsky et al., 2017) (finite $\theta$ NO value), in order to characterize SCD (Lunt et al., 2018);

- Salbutamol administration via a space inhaler $(400 \mu \mathrm{g})$ (Miller et al., 2005);

- Spirometry $15 \mathrm{~min}$ after salbutamol administration to calculate the bronchodilator response as compared to the baseline value;

- ECG recorder withdrawal.

Electrocardiographic recording during the pulmonary function tests was acquired with the Holter recorder SpiderView (ELA Medical, SORIN Group, Clamart, France). Analog data were edited on a SyneScope station and further exported in ASCII files. The files were then processed using the HRV analysis software 1.1 downloaded at ${ }^{1}$ and validated by Pichot et al. (2016).

Four 5 -min periods over the approximately 1 -h recording were selected:

- Two baseline measurements during the normal breathing FRC measurements that were averaged;

- One slow-paced ventilation recording during the slowpaced breathing measurement;

- One recording 10 to $15 \mathrm{~min}$ after salbutamol administration (before spirometry). This time point was chosen according to the results of Eryonucu et al. (2001).

From each 5 min recording time and frequency, the domain HRV variables were calculated. Time-domain variables included the mean sinus heart rate (HR), the standard deviation of the RR intervals (SDNN), the percentage of normal consecutive $\mathrm{RR}$ intervals differing by $\mathrm{N} 50 \mathrm{~ms}$ (pNN-50) and the root mean of squared successive differences (RMSSD). After fast Fourier transform, the power spectrum indices were calculated as recommended (No author, 1996). The spectrum was calculated using Welch's periodogram algorithm with a Hamming window of 256 points, an overlap of 50\%, and a precision of 256 points/Hz. The total power (Ptot), very low frequencies (VLF: 0-0.04 Hz), low frequencies (LFa: $0.04-0.15 \mathrm{~Hz}$ ), and high frequencies (HFa: $0.15-0.40 \mathrm{~Hz}$ ) were calculated. $\mathrm{LFa}$ and $\mathrm{HFa}$ were also expressed as normalized values $\mathrm{LFnu}=100{ }^{*} \mathrm{LFa} /($ Ptot$\mathrm{VLF})$ and HFnu $=100 * \mathrm{HFa} /($ Ptot-VLF), and the LF/HF ratio was calculated.

In accordance with Billman (2013b), LF/HF $=(0.50$ parasympathetic +0.25 sympathetic nerve activity $) /(0.90$ parasympathetic +0.10 sympathetic nerve activity). Thus, an increase in the LF/HF ratio cannot be assumed to necessarily reflect a shift to "sympathetic dominance" and a decrease in this index as a shift to "parasympathetic dominance" (Billman, 2013b). Moreover, there is a non-linear interaction between the LF and HF that further complicates the interpretation of this ratio.

\footnotetext{
${ }^{1}$ httpse://anslabtools.univ-st-etienne.fr.
}

The paced ventilation response (effect of RSA) was calculated as $\Delta$ (stimulated minus baseline condition) of the normalized HF (HFnu).

Since HR variations per se influence HRV responses, frequency data (power spectra) were corrected by division with the corresponding mean R-R interval in seconds (Billman, 2013a), giving $\mathrm{LHa}_{\text {corrected }}$ and $\mathrm{HFa}_{\text {corrected }}$.

Lucini et al. (2018) determined that the HRV variables can be classified in three independent factors that were used: oscillatory domain (HFnu, LFnu, LF/HF ratio, and possibly $\triangle$ HFnu), amplitude domain (Ptot, $\mathrm{HFa}$, and $\mathrm{LFa}$ ) and a pulse domain (HR and mean RR). When HR fluctuations mediated by autonomic nerves are observed in HF band $(>0.15 \mathrm{~Hz})$, it is mediated by the cardiac vagus (Hayano and Yuda, 2019).

All pulmonary function tests and HRV indices were also recorded on a standardized abstraction form.

\section{Statistical Analyses}

Sample size calculation. We planned to include 30 children in each group of patients based on the number of patients included in the previous studies devoted to the ANS function, involving asthmatic or SCD patients (Eryonucu et al., 2001; Pearson et al., 2005; Knight-Madden et al., 2013; Garcia-Araújo et al., 2015).

The results were expressed as median (25-75th percentiles) since most indices followed not normal distribution (HRV indices for instance). Comparisons between the baseline and stimulated conditions were performed using Wilcoxon signedrank test. Comparisons of the continuous variables between the three groups of children were performed using the KruskalWallis test, and subsequent intergroup comparisons were performed using the Mann-Whitney $U$ test. Categorical variables were compared using the chi-square test. Correlations were evaluated using Pearson's correlation coefficient. A $p$ value $<0.05$ was deemed significant. No correction for multiple testing was done due to the pathophysiological design of the study (Rothman, 1990). All statistical analyses were performed with StatView 5.0 software (SAS Institute, Cary, NC, United States).

\section{RESULTS}

The HRV analysis was not obtained for one asthmatic child without SCD, leaving 89 children included. The clinical and functional characteristics of the enrolled patients are described in Table 1. SCD children with asthmatic symptoms were characterized by a more severe disease, as evidenced by the increased frequency of VOC and ACS. Among these asthmatic SCD children, six were suffering from typical atopic asthma involving several members of the family, including parents, without SCD. Thus, the typical asthma prevalence in our SCD children was 6/60 (10\%, 95\% CI: 2-18). Overall, the SCD children were more often treated by a short-acting bronchodilator than asthmatic non-SCD children who received ICS/LABA combination more frequently. 
TABLE 1 | Clinical characteristics of the 89 enrolled children.

\begin{tabular}{|c|c|c|c|c|}
\hline Clinical characteristics & Non asthmatic SCD $N=30$ & Asthmatic SCD $N=30$ & Asthma without SCD N $=29$ & $P$ value \\
\hline Sex, female/male & $18 / 12$ & $14 / 16$ & $18 / 11$ & 0.430 \\
\hline Weight, kg & $40.5[34.0 ; 51.0]$ & $39.5[33.0 ; 49.0]$ & $42.0[38.7 ; 60.5]$ & 0.214 \\
\hline \multicolumn{5}{|l|}{ Asthma characteristics } \\
\hline Typical asthma, $\mathrm{n}$ & 0 & 6 & 29 & ND \\
\hline Controlled asthma, $\mathrm{n}$ & & 14 & 17 & 0.438 \\
\hline SABA, $n$ & & 18 & 7 & 0.002 \\
\hline ICS, n & & 1 & 1 & $>0.999$ \\
\hline LTRA, n & & 0 & 1 & 0.492 \\
\hline ICS/LABA, n & & 11 & 20 & 0.019 \\
\hline \multicolumn{5}{|l|}{ SCD characteristics } \\
\hline VOC\#, n last year & $0.0[0.0 ; 0.5]$ & $1.0[0.0 ; 2.0]$ & & 0.002 \\
\hline ACS, $n$ patients & 5 & 14 & & 0.025 \\
\hline ACS, total number/child & $0.0[0.0 ; 0.0]$ & $0.0[0.0 ; 1.0]$ & & 0.018 \\
\hline Cerebral vasculopathy ${ }^{\star}, \mathrm{n}$ & 7 & 12 & & 0.267 \\
\hline Hydroxyurea & 16 & 20 & & 0.429 \\
\hline Previous transfusion program & 7 & 7 & & $>0.999$ \\
\hline Hemoglobin, g/dL & $9.4[8.4 ; 10.5]$ & $8.5[7.8 ; 9.0]$ & NA & 0.054 \\
\hline Leucocyte count, $\times 10^{+9} / \mathrm{L}$ & $7.7[6.4 ; 10.2]$ & $8.2[7.3 ; 10.3]$ & NA & 0.391 \\
\hline Reticulocyte count, $\times 10^{+9} / \mathrm{L}$ & $188[148 ; 270]$ & $197[147 ; 308]$ & NA & 0.554 \\
\hline Lactic dehydrogenase, IU/L & $491[355 ; 621]$ & $511[418 ; 941]$ & NA & 0.114 \\
\hline
\end{tabular}

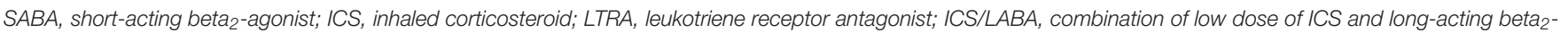

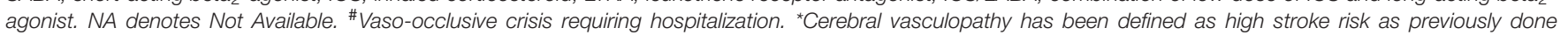
(Sommet et al., 2016).

\section{Pulmonary Function Tests (Table 2 and Table A1)}

Asthmatic subjects, with or without SCD, depicted a mild baseline airflow limitation (reduced $\mathrm{FEV}_{1} / \mathrm{FVC} z$-score) and a higher bronchodilator response than non-asthmatic SCD children. Increased exhaled NO values were observed in nonSCD asthmatic children when compared to SCD children, whether or not they were suffering from asthma. Bronchodilator response positively correlated with both $\mathrm{J}_{\mathrm{aw}, \mathrm{NO}}(R=+0.26$, $p=0.019, n=83)$ and $\mathrm{FENO}_{0.05}(R=+0.22, p=0.043, n=89)$. The median DLCO values\% predicted were elevated in the three groups of children, and even significantly higher in asthmatic non-SCD children as compared to SCD children (see Table A1). The VC/VA values of the SCD groups were higher than that of asthmatic non-SCD children.

\section{Baseline HRV Variability (Table 3)}

Sickle cell disease children were characterized by a reduced HRV (SDNN, Ptot for instance) that was related to the reduced values of both HFa and LFa of similar degrees since the HFnu and LFnu and LF/HF ratio were similar. Thus, only the amplitude domain was decreased. HFnu, and logically LFnu, significantly correlated with the $\mathrm{FEV}_{1} z$-score $(R=0.22, p=0.034, R=-0.23$, $p=0.030$; respectively). No other significant correlation was observed between the HRV parameters and pulmonary function test parameters, which were evaluated since airflow limitation could have been related to enhanced parasympathetic tone.

\section{HRV Variability in Stimulated Conditions (Paced Ventilation, Salbutamol)}

In the whole population $(n=89)$, as compared with the baseline, paced ventilation was associated with a significant increase in Ptot $\left(6418 \mathrm{~ms}^{2}\right.$ [3384; 10294] versus 3497 [1941; 6422], $\left.p<0.001\right)$ that was related to an increase in LFa $\left(3743 \mathrm{~ms}^{2}[1401 ; 7460]\right.$ versus 875 [456; 1689], $p<0.001)$. Both HFa $(p=0.088)$ and HR were not modified ( 88 beats/min $[83 ; 95]$ versus 89 [80; 97], $n=89 ; p=0.359)$. The LH/HF ratio significantly increased with paced ventilation $(5.5[1.5 ; 11.3]$ versus 1.17 [0.79; 1.80$]$, $p<0.001)$. Thus, both amplitude and oscillatory domains were modified. Additionally, as compared to baseline, HFa under paced ventilation significantly decreased in non-SCD asthmatic children $(p<0.001, n=29)$ while it did not decrease in SCD children $(p=0.497, n=60)$, explaining the trend evidenced in the whole population $(n=89)$.

The response to paced ventilation differed among the three groups and is described in Figure 1; asthmatic non-SCD children 
TABLE 2 | Lung functional characteristics of the 89 enrolled children.

\begin{tabular}{|c|c|c|c|c|c|}
\hline Functional characteristics & $\begin{array}{c}\text { Non asthmatic SCD } \\
N=30 \text { (group } 1)\end{array}$ & $\begin{array}{l}\text { Asthmatic SCD } \\
N=30 \text { (group 2) }\end{array}$ & $\begin{array}{c}\text { Asthma without SCD } \\
\qquad N=29 \text { (group } 3 \text { ) }\end{array}$ & $P$ Value & $\begin{array}{c}\text { Intergroup } \\
\text { Comparisons }\end{array}$ \\
\hline \multicolumn{6}{|l|}{ Baseline lung function } \\
\hline $\mathrm{FEV}_{1 ;}$ L & $2.17[1.65 ; 2.64]$ & $1.97[1.55 ; 2.38]$ & $2.06[1.83 ; 2.50]$ & 0.383 & \\
\hline $\mathrm{FEV}_{1}, \%$ predicted & $101[85 ; 106]$ & $88[78 ; 97]$ & $100[92 ; 105]$ & 0.003 & $2<1=3$ \\
\hline $\mathrm{FEV}_{1}$ z-score & $+0.07[-1.17 ;+0.46]$ & $-0.89[-1.65 ;-0.26]$ & $+0.00[-0.60 ;+0.50]$ & 0.003 & $2<1=3$ \\
\hline FVC, L & $2.34[1.94 ; 2.93]$ & $2.28[1.87 ; 2.75]$ & $2.49[2.22 ; 3.01]$ & 0.334 & \\
\hline FVC, \% predicted & $99[86 ; 105]$ & $95[84 ; 102]$ & $105[99 ; 118]$ & 0.001 & $1=2<3$ \\
\hline FVC, z-score & $-0.08[-1.15 ;+0.41]$ & $-0.43[-1.24 ;+0.16]$ & $+0.40[-0.05 ;+1.44]$ & 0.001 & $1=2<3$ \\
\hline $\mathrm{FEV}_{1} / \mathrm{FVC}$ & $0.89[0.86 ; 0.90]$ & $0.84[0.80 ; 0.86]$ & $0.83[0.79 ; 0.86]$ & 0.001 & $1>2=3$ \\
\hline $\mathrm{FEV}_{1} / \mathrm{FVC}, \mathrm{z}$-score & $-0.00[-0.44 ;+0.53]$ & $-0.71[-1.25 ;-0.29]$ & $-0.99[-1.57 ;-0.25]$ & 0.001 & $1>2=3$ \\
\hline \multicolumn{6}{|l|}{ Exhaled NO* } \\
\hline $\mathrm{C}_{\mathrm{alv}, \mathrm{NO}}, \mathrm{ppb}(n=83)$ & $3.2[2.3 ; 5.3]$ & $3.4[1.6 ; 5.4]$ & $7.1[3.3 ; 11.4]$ & 0.003 & $1=2<3$ \\
\hline $\mathrm{J}_{\mathrm{aw}}, \mathrm{NO}, \mathrm{nL} / \min (n=83)$ & $22[16 ; 35]$ & $16[9 ; 46]$ & $57[24 ; 104]$ & 0.001 & $1=2<3$ \\
\hline $\mathrm{FENO}_{005}, \mathrm{Ppb}(n=89)$ & $10.3[6.9 ; 15.0]$ & $8.0[5.4 ; 18.8]$ & $20.8[13.8 ; 34.5]$ & 0.001 & $1=2<3$ \\
\hline \multicolumn{6}{|l|}{ Post-bronchodilator } \\
\hline $\mathrm{FEV}_{1} \mathrm{~L}$ & $2.18[1.73 ; 2.69]$ & $2.07[1.70 ; 2.45]$ & $2.19[1.92 ; 2.64]$ & 0.425 & \\
\hline $\mathrm{FEV}_{1}, \%$ predicted & $104[89 ; 109]$ & $94[87 ; 103]$ & $108[102 ; 117]$ & 0.001 & $1=2<3$ \\
\hline $\mathrm{FEV}_{1}, \mathrm{z}$-score & $+0.30[-0.86 ;+0.64]$ & $-0.49[-1.03 ;+0.24]$ & $+0.63[+0.15 ;+1.33]$ & 0.001 & $1=2<3$ \\
\hline Bronchodilator response, \% & $+3[-1 ;+5]$ & $+4[+2 ;+9]$ & $+7[+3 ;+12]$ & 0.004 & $1<2=3$ \\
\hline FVC, L & $2.40[1.97 ; 2.85]$ & $2.29[1.98 ; 2.74]$ & $2.51[2.27 ; 3.15]$ & 0.277 & \\
\hline FVC, \% predicted & $100[86 ; 107]$ & $96[86 ; 104]$ & $110[102 ; 117]$ & 0.001 & $1=2<3$ \\
\hline FVC, z-score & $+0.02[-1.09 ;+0.51]$ & $-0.34[-1.11 ;+0.32]$ & $+0.77[+0.15 ;+1.33]$ & 0.001 & $1=2<3$ \\
\hline $\mathrm{FEV}_{1} / \mathrm{FVC}$ & $0.91[0.88 ; 0.92]$ & $0.88[0.84 ; 0.91]$ & $0.86[0.83 ; 0.90]$ & 0.005 & $1>2=3$ \\
\hline $\mathrm{FEV}_{1} / \mathrm{FVC}, \mathrm{z}$-score & $+0.47[-0.25 ;+0.73]$ & $+0.05[-0.52 ;+0.36]$ & $-0.36[-0.74 ;+0.16]$ & 0.008 & $1>2=3$ \\
\hline
\end{tabular}

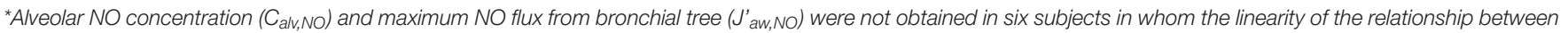

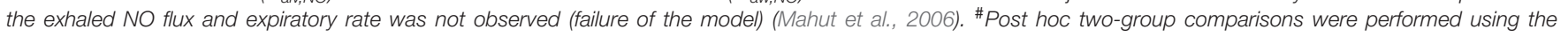
Mann-Whitney U test or the chi-square test, as appropriate (see section "Materials and Methods"). For additional lung function tests, see Table A1.

TABLE 3 | Baseline heart rate variability characteristics of the 89 enrolled children.

\begin{tabular}{|c|c|c|c|c|c|}
\hline $\begin{array}{l}\text { Functional characteristics } \\
\text { Baseline HRV }\end{array}$ & $\begin{array}{l}\text { Non asthmatic SCD } \\
N=30 \text { (group 1) }\end{array}$ & $\begin{array}{l}\text { Asthmatic SCD } \\
N=30 \text { (group 2) }\end{array}$ & $\begin{array}{l}\text { Asthma without SCD } \\
N=29 \text { (group } 3 \text { ) }\end{array}$ & $P$ value & $\begin{array}{l}\text { Intergroup } \\
\text { comparisons }\end{array}$ \\
\hline \multicolumn{6}{|l|}{ Pulse domain } \\
\hline $\mathrm{RR}, \mathrm{ms}$ & 680 [619; 714] & 682 [649; 736] & 685 [639; 747] & 0.696 & \\
\hline $\mathrm{HR}$, beats/min & $89[85 ; 97]$ & 89 [82; 93] & 88 [82; 95] & 0.755 & \\
\hline \multicolumn{6}{|l|}{ Amplitude domain } \\
\hline pNN50, \% & $26[13 ; 41]$ & $18[7 ; 33]$ & $29[15 ; 39]$ & 0.118 & \\
\hline SDNN, ms & $60[48 ; 74]$ & $54[40 ; 83]$ & $75[61 ; 97]$ & 0.006 & $1=2<3$ \\
\hline RMSSD, ms & $45[32 ; 63]$ & $40[27 ; 66]$ & $53[37 ; 75]$ & 0.128 & \\
\hline Ptot, $\mathrm{ms}^{2}$ & 3454 [1824; 5017] & 2264 [1187; 4947] & 5396 [3246; 7397] & 0.007 & $1=2<3$ \\
\hline VLF, $\mathrm{ms}^{2}$ & 1006 [592; 2209] & 779 [387; 1588] & $1686[1124 ; 3146]$ & 0.012 & $1=2<3$ \\
\hline $\mathrm{LFa}, \mathrm{ms}^{2}$ & 857 [449; 1414] & 593 [366; 1430] & 1318 [669; 1925] & 0.028 & $1=2<3$ \\
\hline $\mathrm{HFa}, \mathrm{ms}^{2}$ & 924 [446; 1453] & $661[327 ; 1145]$ & 1414 [692; 2288] & 0.010 & $1=2<3$ \\
\hline \multicolumn{6}{|l|}{ Oscillatory domain } \\
\hline LFnu, \% & $44[35 ; 50]$ & $48[35 ; 55]$ & $45[30 ; 55]$ & 0.760 & \\
\hline HFnu, \% & $39[31 ; 50]$ & $41[30 ; 48]$ & $41[32 ; 51]$ & 0.672 & \\
\hline LF/HF ratio & $1.19[0.94 ; 1.64]$ & $1.16[0.83 ; 1.91]$ & 1.19 [0.61; 1.80$]$ & 0.686 & \\
\hline
\end{tabular}

were characterized by lower HFnu during paced ventilation when compared to SCD children while their HFa values were similar. Asthmatic non-SCD children exhibited a higher decrease in $\triangle$ HFnu. This decrease correlated with VC/VA (Figure 2). HFnu during paced ventilation also correlated with VC/VA $(R=0.373, p<0.001)$.
In the whole population $(n=89)$, as compared with baseline, salbutamol administration was associated with a significant increase in HR (95 beats/min [92; 102] versus 88 [83; 95], $p<0.001$ ), which was even higher in SCD children when compared to asthmatic non-SCD children: 97 beats/min [93; 105] versus $94[87 ; 95](p=0.024)$. Ptot significantly decreased after 

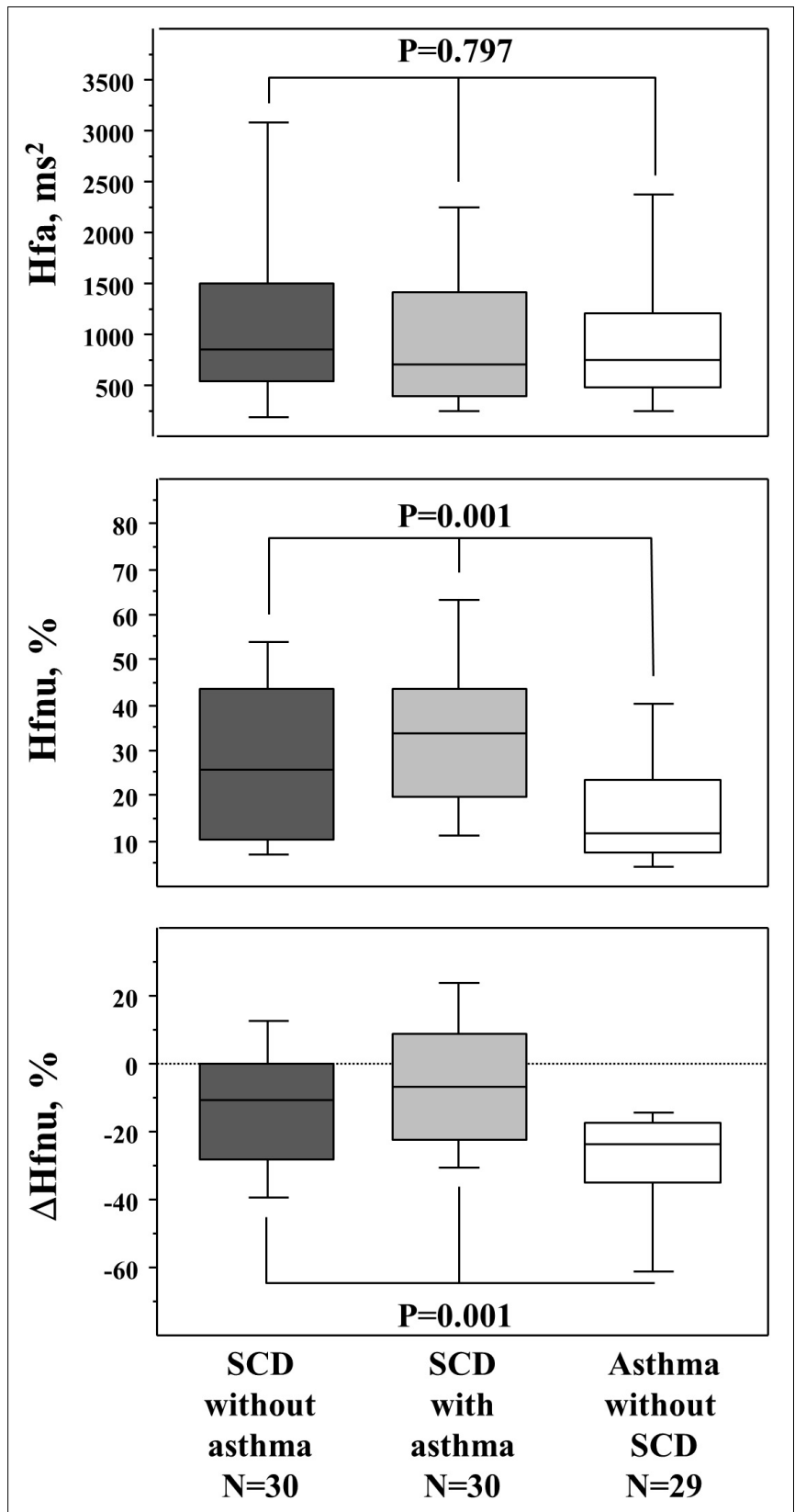

FIGURE 1 | Response to paced ventilation (respiratory sinus arrhythmia evaluation). The upper panel is the HFa (raw values of HF), the middle panel is the normalized HF ( $\mathrm{Hfnu}$ ), and the lower panel is the $\Delta \mathrm{HFnu}$ (stimulated minus baseline condition). $p$ values are those of the Kruskal-Wallis test between the three groups. The Mann-Whitney $U$ test further demonstrated that the two SCD groups differed from the asthmatic non-SCD group in the middle and lower panels (data not shown). Box and whisker plots show median, 25 and 75th percentiles, and 10 and 90th percentiles.

salbutamol when compared to the baseline condition $\left(2754 \mathrm{~ms}^{2}\right.$ [1583; 4882] versus 3497 [1941; 6422], $p=0.014)$, which was mainly related to a significant decrease in $\mathrm{HFa}\left(503 \mathrm{~ms}^{2}\right.$ [233; 937] versus 943 [435; 1710], $p<0.001)$. This decrease remained significant even correcting for the $\mathrm{HR}$ modification: $\mathrm{HFa}_{\text {corrected, }}$, salbutamol $=831 \mathrm{~ms}^{2} / \mathrm{s}[370 ; 1392]$ versus baseline $=1410 \mathrm{~ms}^{2} / \mathrm{s}$

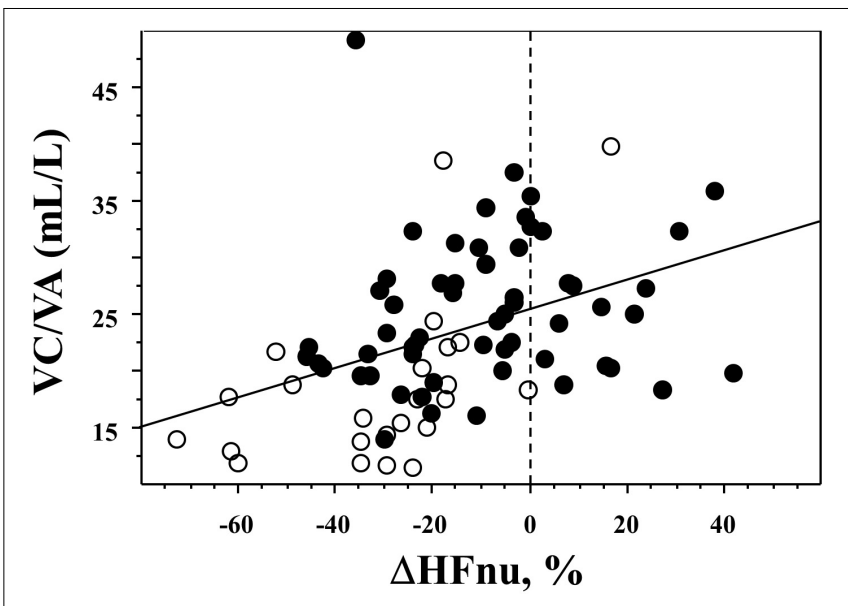

FIGURE 2 | Relationship between the effect of paced ventilation and VCNA. A significant correlation was evidenced between VC/VA and $\triangle \mathrm{HFnu}$ :

$R=0.406, p=0.0002$. Black circles are SDC children while open circles are asthmatic non-SCD children.

[697; 2236], $p<0.001$. Salbutamol administration was associated with a significant increase in the LF/HF ratio $(1.57$ [0.98; 2.58] versus 1.17 [0.79; 1.80$], p=0.005)$. Thus, the three domains of HRV were modified.

The response to salbutamol also differed between the three groups since asthmatic non-SCD children depicted a lower LF/HF ratio when compared to SCD children (Figure 3) and since they also depicted a higher HFnu (36\% [29; 43]) versus the two SCD groups (non-asthmatic: $29 \%$ [20; 42] and asthmatic: $29 \%[19 ; 40] ; p=0.046)$.

\section{HRV Variability in Subgroups of SCD Children}

Overall, there was no difference among all the HRV parameters between the two groups of SCD children. It has previously been emphasized that ANS dysfunction could be a marker of SCD severity; we therefore assessed ANS functions in SCD children with $(n=49)$ and without $(n=11)$ hospitalization for VOC, demonstrating that HFnu and $\triangle$ HFnu under paced ventilation were significantly different in children without any hospitalization for VOC $(15 \%[7 ; 24]$ and $-23 \%[-32 ;-8]$, respectively) when compared to those with $(39 \%[19 ; 45]$ and $-6 \%[-24 ;+6]$, respectively; $p=0.011$ and $p=0.030)$. As previously done by Knight-Madden et al. (2013), we compared SCD children with and without history of a ACS showing that children who already had an ACS, when compared to those without a previous ACS, were characterized by lower values of both baseline $\mathrm{HFa}\left(404 \mathrm{~ms}^{2}\right.$ [228; 895] versus $931 \mathrm{~ms}^{2}$ [601; 1345], respectively; $p=0.046)$ and $\mathrm{pNN} 50(13 \%$ [6;25] versus $28 \%$ [12; $41]$, respectively; $p=0.029)$, the latter being correlated with the number of ACS events $(R=-0.29, p=0.023)$.

Genotype is also a marker of severity; we compared HRV indices in severe genotypes (SS and $\beta^{\circ}, n=51$ ) as compared to a less severe genotype (SC, $n=9$ ), demonstrating the absence of difference for any index. 


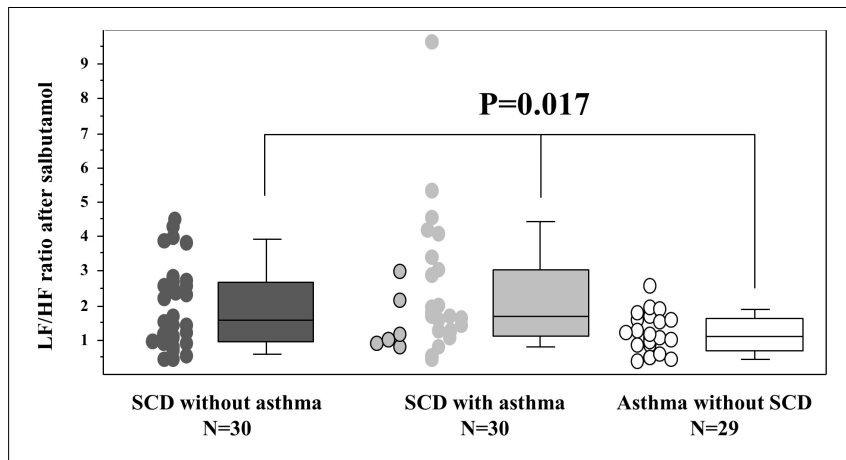

FIGURE 3 | Response to salbutamol stimulation. Sympathetic stimulation was obtained after $400 \mu \mathrm{g}$ of salbutamol administration (10 min after inhalation). The six SCD patients with typical asthma are individualized in the SCD asthma group as circles on the left side of the group with the black contour line. The $p$ value is that of the Kruskal-Wallis test between the three groups. The Mann-Whitney $U$ tests further demonstrated that the two SCD groups differed from the asthmatic non-SCD group (data not shown). The box and whisker plots show median, 25 and 75th percentiles, and 10 and 90th percentiles.

\section{DISCUSSION}

Our cross-sectional pathophysiological study demonstrates that SCD children are characterized by a decreased HRV in the resting condition that further decreased upon salbutamol administration. Our working hypothesis was that either asthma diagnosis or bronchodilator treatment might aggravate SCD via their modulating effect on ANS. Our results argue for the latter hypothesis since ANS functions were similar in the two groups of SCD children while that with asthma had more vaso-occlusive events. As a consequence, these events may have been precipitated by salbutamol administration, which warrants further clinical demonstration.

\section{Representativeness of the Three Groups}

Sickle cell disease children with asthma-like symptoms were characterized by some degree of airflow limitation and bronchodilator response when compared to non-asthmatic SCD children, explaining the prescription of asthma treatment that was mainly SABA for a cough or wheezing episodes. SCD children with asthma depicted a more severe disease according to the incidence of VOC and ACS. SCD patients with a diagnosis of asthma did not exhibit increased exhaled NO values, as previously demonstrated (Delclaux et al., 2005; Cohen et al., 2016). Asthmatic non-SCD children were characterized by an increase in exhaled NO that explained the relationship between bronchodilator response and exhaled NO, as previously evidenced (Mahut et al., 2010). They also demonstrated an increased DLCO\% predicted as previously evidenced in asthmatic patients (Stewart, 1988), while their VC/VA values were lower than those of SCD children, as expected (Delclaux et al., 2005). Asthmatic SCD and asthmatic non-SCD children were clearly differentiated from a pathophysiological point of view, even if a restricted number of SCD children had typical asthma. Overall, despite the small sample of patients, every single group may seem representative of each disease state previously described.

\section{Representativeness of HRV}

The interpretation of HRV results is a challenging issue (Billman, 2013b; Lucini et al., 2018). The first issue deals with the results of stimulated conditions when compared to the baseline condition. Stimulation by paced ventilation induced an increase in the HRV (increase in Ptot) that was related to LFa that resulted in an increase in the LF/HF ratio as previously evidenced in asthmatic and control subjects using a similar breathing pattern (Anderson et al., 2009; Garcia-Araújo et al., 2015). Stimulation by salbutamol administration induced an increase in $\mathrm{HR}$, a decrease in Ptot and $\mathrm{HFa}$, and an increase in LF/HF ratio as previously demonstrated in asthmatic children (Jartti et al., 1997). As a consequence, our stimulated conditions reproduced the findings of previous authors in asthmatic patients. Furthermore, the correlation between $\mathrm{FEV}_{1}$ and both LHnu and HFnu has previously been evidenced in both asthmatic and healthy subjects (Garcia-Araújo et al., 2015).

\section{HRV Interpretation}

In the baseline condition, SCD children were characterized by a frank reduction in HRV with a similar LF/HF ratio than asthmatic non-SCD children, suggesting an autonomic dysfunction in the form of impaired parasympathetic tone and sympathetic overactivity, demonstrated by previous authors using continuous non-invasive blood pressure and peripheral vascular resistance (Chalacheva et al., 2015). Interestingly, Chalacheva et al. (2015) recently demonstrated that low parasympathetic activity at baseline dramatically increased the probability of belonging to a peripheral vasoconstriction endotype in SCD subjects, even after adjusting for hemoglobin level, suggesting a characteristic ANS dysfunction that is independent of anemia (Chalacheva et al., 2019).

Paced ventilation induced an increase in Ptot, LFa, and LF/HF ratio that was expected (Hayano and Yuda, 2019). Whereas $\mathrm{HFa}$ decreased in asthmatic children as usually evidenced in healthy subjects, this decrease was not observed in SCD children. RSA ensures optimal ventilation-perfusion matching within the lungs (Hayano and Yuda, 2019), which is defective in SCD patients (Pianosi et al., 1991) who are characterized by an increased lung capillary blood volume (Delclaux et al., 2005). We show that the increased VC/VA of SCD children is associated with lesser effect of RSA; thus, an already recruited vascular bed is associated with the loss of RSA effect, which may participate to the mild degree of hypoxemia in SCD patients (Delclaux et al., 2005). These effects of respiratory parameters on the RSA operate independently of the level of cardiac vagal activity (Hayano and Yuda, 2019). When respiration frequency is $<0.15 \mathrm{~Hz}, \mathrm{RSA}$ becomes a part of the LF component, as observed in our study, and the association between HF component and cardiac vagal function is lost (Hayano and Yuda, 2019). Asthmatic non-SCD children were characterized by a more frank decrease in HF as compared to SCD children. Even though the ANS cannot transfer $\mathrm{HRV}>0.15 \mathrm{~Hz}$, it may restrict the magnitude of cardiac vagal modulations of heart rate (Hayano and Yuda, 2019), which may 
explain the observed effects. Thus, the different effects of paced ventilation in SCD and non-SCD children may be explained by the increased sympathetic modulation in SCD.

More importantly for our study question, the two groups of SCD children were similar, suggesting that the diagnosis of asthma per se did not modify ANS functions. Since the SCD children with asthma-like symptoms were characterized by an increased prevalence of both VOC and ACS, one may, therefore, hypothesize that asthma treatment could have been involved in vaso-occlusive events. Along this line, salbutamol administration in SCD children further modified the ANS balance toward a deregulated profile similar to that observed during VOC. Charlot et al. (2017) showed that HFa decreased during VOC compared to the steady state, suggesting parasympathetic withdrawal that certainly caused the dominance of the sympathetic activity over the parasympathetic activity, as reflected by the increase in LF/HF during VOC. Finally, we show that markers of SCD severity (hospitalization for VOC or occurrence of ACS) were associated with ANS modifications that may suggest parasympathetic withdrawal, as previously evidenced for ACS (Knight-Madden et al., 2013).

The baseline modifications of HRV could be related to betaadrenergic stimulation, which has been shown to result in a significant decrease in time domain measures of HRV (Ahmed et al., 1994). Epinephrine has also been shown to promote red blood cell adhesion and vaso-occlusion in SCD (Zennadi et al., 2007). Moreover, genetic variation in the beta-1 (Ashley-Koch et al., 2008) and beta-2 (Jhun et al., 2019) adrenergic receptors has been shown to influence pulmonary hypertension prevalence and chronic pain severity in SCD. Thus, sympathetic nervous system inhibition may be a therapeutic approach in SCD.

For years, the scientific community has worked under the paradigm that the asthma exacerbation, not the treatment, is the likely trigger for VOC. This made sense because asthma exacerbation limits airflow and oxygenation that would worsen sickling. Nevertheless, Sangkatumvong et al. (2011) have shown that desaturation did not induce change in microvascular perfusion in SCD patients. Therefore, other mechanisms had to be found to justify this high risk of VOC, which was the subject of this study.

\section{Limitations of the Study}

Our study has limitations due to its design. We did not include healthy control children. Nevertheless, our objective was to assess whether the pathophysiology of asthmatic SCD was similar to that of asthmatic without SCD since one may have initially hypothesized that asthmatic SCD would depict similar findings than asthmatic without SCD when compared to SCD children without asthma, justifying their severity and our design. Furthermore, ANS comparisons have previously been obtained between both asthmatic and healthy subjects and between SCD patients and healthy subjects, showing that baseline HRV is similar in asthmatic patients and healthy subjects (Nebor et al., 2011; Garcia-Araújo et al., 2015). Importantly, our data have been obtained in baseline stable condition, which is probably not representative of the setting leading to salbutamol administration, i.e., asthma-like symptoms indicating
SCD worsening. Finally, our results do not demonstrate the causality relationship between salbutamol administration and increased vaso-occlusive events in SCD children, which remains to be further evaluated in a prospective design.

In conclusion, these data suggest that SCD children have altered autonomic activity that is worsened by salbutamol administration.

\section{DATA AVAILABILITY STATEMENT}

The datasets generated for this study are available on request to the corresponding author.

\section{ETHICS STATEMENT}

The studies involving human participants were reviewed and approved by the Ethics Committee, Comité de Proctection des Personnes hosted by Hospices Civils de Lyon (CPP SUD-EST II, 2017-17-AM1). Written informed consent to participate in this study was provided by the participants' legal guardian/next of kin.

\section{AUTHOR CONTRIBUTIONS}

$\mathrm{PB}, \mathrm{MB}, \mathrm{CP}$, and $\mathrm{CD}$ conceived the study. $\mathrm{PB}, \mathrm{ID}$, and $\mathrm{CD}$ design the study. HE, NM, LH, and CP acquired the data. HE, $\mathrm{PB}$, and $\mathrm{CD}$ analyzed the data. ID, CP, NM, LH, MB, PB, and $\mathrm{CD}$ interpreted the data. All authors drafted the manuscript, critically revised the manuscript for important intellectual content, approved the final manuscript for publication, and agreed to be accountable for all aspects of the work in ensuring that questions related to the accuracy or integrity of any part of the work are appropriately investigated and resolved. CD had full access to all the data in the study and that he takes responsibility for the integrity of the data and the accuracy of the data analysis, including and especially any adverse effects.

\section{FUNDING}

Financial support for this study was provided by an institutional source, Legs Poix (Poix Legacy Fund, Chancellery of Paris Universities, Paris, France) that had no other role. The Assistance Publique-Hôpitaux de Paris (DRCI) was the sponsor of the study (DrepaSympa study-K170302).

\section{ACKNOWLEDGMENTS}

The authors wish to thank the technicians/nurses of the Pulmonary Function Testing Unit of Robert Debré Hospital for expert technical assistance: Mrs. Martine Guyon, Chrystelle Jeanminet Perez, Sandra Marguillier, Eliane Muabila, Isabelle Savioz, Karine Zakine, and Mr. Jean-Claude Sismeiro. 


\section{REFERENCES}

Ahmed, M. W., Kadish, A. H., Parker, M. A., and Goldberger, J. J. (1994). Effect of physiologic and pharmacologic adrenergic stimulation on heart rate variability. J. Am. Coll. Cardiol. 24, 1082-1090. doi: 10.1016/0735-1097(94)90874-5

Anderson, D. E., McNeely, J. D., and Windham, B. G. (2009). Device-guided slowbreathing effects on end-tidal $\mathrm{CO}(2)$ and heart-rate variability. Psychol. Health Med. 14, 667-679. doi: 10.1080/13548500903322791

Ashley-Koch, A. E., Elliott, L., Kail, M. E., De Castro, L. M., Jonassaint, J., Jackson, T. L., et al. (2008). Identification of genetic polymorphisms associated with risk for pulmonary hypertension in sickle cell disease. Blood 111, 5721-5726. doi: 10.1182/blood-2007-02-074849

Billman, G. E. (2013a). The effect of heart rate on the heart rate variability response to autonomic interventions. Front. Physiol. 4:222. doi: 10.3389/fphys.2013. 00222

Billman, G. E. (2013b). The LF/HF ratio does not accurately measure cardiac sympatho-vagal balance. Front. Physiol. 4:26. doi: 10.3389/fphys.2013.00026

Chalacheva, P., Kato, R. M., Sangkatumvong, S., Detterich, J., Bush, A., Wood, J. C., et al. (2015). Autonomic responses to cold face stimulation in sickle cell disease: a time-varying model analysis. Physiol. Rep. 3:e12463. doi: 10.14814/ phy2.12463

Chalacheva, P., Kato, R. M., Shah, P., Veluswamy, S., Denton, C. C., Sunwoo, J., et al. (2019). Sickle cell disease subjects have a distinct abnormal autonomic phenotype characterized by peripheral vasoconstriction with blunted cardiac response to head-up tilt. Front. Physiol. 10:381. doi: 10.3389/fphys.2019.00381

Charlot, K., Hierso, R., Lemonne, N., Romana, M., Tressières, B., Lalanne-Mistrih, M.-L., et al. (2017). Changes in autonomic nervous activity during vasoocclusive crisis in patients with sickle cell anaemia. Br. J. Haematol. 177, 484-486. doi: 10.1111/bjh.14064

Cohen, R. T., Rodeghier, M., Kirkham, F. J., Rosen, C. L., Kirkby, J., DeBaun, M. R., et al. (2016). Exhaled nitric oxide: not associated with asthma, symptoms, or spirometry in children with sickle cell anemia. J. Allergy Clin. Immunol. 138, 1338-1343.e4. doi: 10.1016/j.jaci.2016.06.043

Delclaux, C., Zerah-Lancner, F., Bachir, D., Habibi, A., Monin, J.-L., Godeau, B., et al. (2005). Factors associated with dyspnea in adult patients with sickle cell disease. Chest 128, 3336-3344. doi: 10.1378/chest.128.5.3336

Edgell, H., Moore, L. E., Chung, C., Byers, B. W., and Stickland, M. K. (2016). Short-term cardiovascular and autonomic effects of inhaled salbutamol. Respir. Physiol. Neurobiol. 231, 14-20. doi: 10.1016/j.resp.2016.05.014

Eryonucu, B., Uzun, K., Güler, N., and Bilge, M. (2001). Comparison of the acute effects of salbutamol and terbutaline on heart rate variability in adult asthmatic patients. Eur. Respir. J. 17, 863-867. doi: 10.1183/09031936.01.17508630

Garcia-Araújo, A. S., Pires Di Lorenzo, V. A., Labadessa, I. G., Jürgensen, S. P., Di Thommazo-Luporini, L., Garbim, C. L., et al. (2015). Increased sympathetic modulation and decreased response of the heart rate variability in controlled asthma. J. Asthma 52, 246-253. doi: 10.3109/02770903.2014.957765

Garrard, C. S., Seidler, A., McKibben, A., McAlpine, L. E., and Gordon, D. (1992). Spectral analysis of heart rate variability in bronchial asthma. Clin. Auton. Res. 2, 105-111. doi: 10.1007/bf01819665

Glassberg, J., Spivey, J. F., Strunk, R., Boslaugh, S., and DeBaun, M. R. (2006). Painful episodes in children with sickle cell disease and asthma are temporally associated with respiratory symptoms. J. Pediatr. Hematol. Oncol. 28, 481-485. doi: 10.1097/01.mph.0000212968.98501.2b

Glassberg, J. A., Strunk, R., and DeBaun, M. R. (2014). Wheezing in children with sickle cell disease. Curr. Opin. Pediatr. 26, 9-18. doi: 10.1097/MOP. 0000000000000045

Hayano, J., and Yuda, E. (2019). Pitfalls of assessment of autonomic function by heart rate variability. J. Physiol. Anthropol. 38:3. doi: 10.1186/s40101-019-0 193-2

Hill, L. K., Hu, D. D., Koenig, J., Sollers, J. J., Kapuku, G., Wang, X., et al. (2015). Ethnic differences in resting heart rate variability: a systematic review and meta-analysis. Psychosom. Med. 77, 16-25. doi: 10.1097/PSY.00000000000 00133

Jartti, T., Kaila, T., Tahvanainen, K., Kuusela, T., Vanto, T., and Välimäki, I. (1997). The acute effects of inhaled salbutamol on the beat-to-beat variability of heart rate and blood pressure assessed by spectral analysis. Br. J. Clin. Pharmacol. 43, 421-428. doi: 10.1046/j.1365-2125.1997.00565.x
Jhun, E. H., Sadhu, N., Hu, X., Yao, Y., He, Y., Wilkie, D. J., et al. (2019). Beta2adrenergic receptor polymorphisms and haplotypes associate with chronic pain in sickle cell disease. Front. Pharmacol. 10:84. doi: 10.3389/fphar.2019. 00084

Knight-Madden, J. M., Connes, P., Bowers, A., Nebor, D., Hardy-Dessources, M.D., Romana, M., et al. (2013). Relationship between acute chest syndrome and the sympatho-vagal balance in adults with hemoglobin SS disease; a case control study. Clin. Hemorheol. Microcirc. 53, 231-238. doi: 10.3233/CH-20121545

Lucini, D., Solaro, N., and Pagani, M. (2018). Autonomic differentiation map: a novel statistical tool for interpretation of heart rate variability. Front. Physiol. 9:401. doi: 10.3389/fphys.2018.00401

Lunt, A., Mortimer, L., Rees, D., Height, S., Thein, S. L., and Greenough, A. (2018). Heterogeneity of respiratory disease in children and young adults with sickle cell disease. Thorax 73, 575-577. doi: 10.1136/thoraxjnl-2017210206

Mahut, B., Delclaux, C., Tillie-Leblond, I., Gosset, P., Delacourt, C., Zerah-Lancner, F., et al. (2004). Both inflammation and remodeling influence nitric oxide output in children with refractory asthma. J. Allergy Clin. Immunol. 113, 252-256. doi: 10.1016/j.jaci.2003.10.038

Mahut, B., Louis, B., Zerah-Lancner, F., and Delclaux, C. (2006). Validity criteria and comparison of analytical methods of flow-independent exhaled NO parameters. Respir. Physiol. Neurobiol. 153, 148-156. doi: 10.1016/j.resp.2005. 10.005

Mahut, B., Peiffer, C., Thibaudon, M., Chevalier-Bidaud, B., Defrance-Hutinet, M.-F., Trinquart, L., et al. (2009). What does a single exhaled nitric oxide measurement tell us in asthmatic children? J. Asthma 46, 810-814. doi: 10.3109/ 02770900903114580

Mahut, B., Trinquart, L., Bokov, P., Peiffer, C., and Delclaux, C. (2010). The link between exhaled NO and bronchomotor tone depends on the dose of inhaled steroid in asthma. Respir. Med. 104, 945-950. doi: 10.1016/j.rmed.2010. 02.003

Mehari, A., and Klings, E. S. (2016). Chronic pulmonary complications of sickle cell disease. Chest 149, 1313-1324. doi: 10.1016/j.chest.2015. 11.016

Miller, M. R., Hankinson, J., Brusasco, V., Burgos, F., Casaburi, R., Coates, A., et al. (2005). Standardisation of spirometry. Eur. Respir. J. 26, 319-338. doi: $10.1183 / 09031936.05 .00034805$

Nebor, D., Bowers, A., Hardy-Dessources, M.-D., Knight-Madden, J., Romana, M., Reid, H., et al. (2011). Frequency of pain crises in sickle cell anemia and its relationship with the sympatho-vagal balance, blood viscosity and inflammation. Haematologica 96, 1589-1594. doi: 10.3324/haematol.2011. 047365

No author, (1996). Heart rate variability: standards of measurement, physiological interpretation and clinical use. Task force of the european society of cardiology and the north american society of pacing and electrophysiology. Circulation 93 1043-1065. doi: 10.1161/01.cir.93.5.1043

Pearson, S. R., Alkon, A., Treadwell, M., Wolff, B., Quirolo, K., and Boyce, W. T. (2005). Autonomic reactivity and clinical severity in children with sickle cell disease. Clin. Auton. Res. 15, 400-407. doi: 10.1007/s10286-0050300-9

Pianosi, P., D'Souza, S. J., Esseltine, D. W., Charge, T. D., and Coates, A. L. (1991). Ventilation and gas exchange during exercise in sickle cell anemia. Am. Rev. Respir. Dis. 143, 226-230. doi: 10.1164/ajrccm/143.2.226

Pichot, V., Roche, F., Celle, S., Barthélémy, J.-C., and Chouchou, F. (2016). HRVanalysis: a free software for analyzing cardiac autonomic activity. Front. Physiol. 7:557. doi: 10.3389/fphys.2016.00557

Romero Mestre, J. C., Hernández, A., Agramonte, O., and Hernández, P. (1997). Cardiovascular autonomic dysfunction in sickle cell anemia: a possible risk factor for sudden death? Clin. Auton. Res. 7, 121-125. doi: 10.1007/bf0230 8838

Rothman, K. J. (1990). No adjustments are needed for multiple comparisons. Epidemiology 1, 43-46. doi: 10.1097/00001648-199001000-00010

Sangkatumvong, S., Khoo, M. C. K., Kato, R., Detterich, J. A., Bush, A., Keens, T. G., et al. (2011). Peripheral vasoconstriction and abnormal parasympathetic response to sighs and transient hypoxia in sickle cell disease. Am. J. Respir. Crit. Care Med. 184, 474-481. doi: 10.1164/rccm.201103-0537OC 
Sommet, J., Alberti, C., Couque, N., Verlhac, S., Haouari, Z., Mohamed, D., et al. (2016). Clinical and haematological risk factors for cerebral macrovasculopathy in a sickle cell disease newborn cohort: a prospective study. Br. J. Haematol. 172, 966-977. doi: 10.1111/bjh.13916

Stewart, R. I. (1988). Carbon monoxide diffusing capacity in asthmatic patients with mild airflow limitation. Chest 94, 332-336. doi: 10.1378/chest.94.2.332

Sylvester, K. P., Patey, R. A., Broughton, S., Rafferty, G. F., Rees, D., Thein, S. L., et al. (2007). Temporal relationship of asthma to acute chest syndrome in sickle cell disease. Pediatr. Pulmonol. 42, 103-106. doi: 10.1002/ppul.20430

Wanger, J., Clausen, J. L., Coates, A., Pedersen, O. F., Brusasco, V., Burgos, F., et al. (2005). Standardisation of the measurement of lung volumes. Eur. Respir. J. 26, 511-522. doi: 10.1183/09031936.05.00035005

Zavorsky, G. S., Hsia, C. C. W., Hughes, J. M. B., Borland, C. D. R., Guénard, H., van der Lee, I., et al. (2017). Standardisation and application of the single-breath determination of nitric oxide uptake in the lung. Eur. Respir. J. 49:1600962. doi: 10.1183/13993003.00962-2016
Zennadi, R., Moeller, B. J., Whalen, E. J., Batchvarova, M., Xu, K., Shan, S., et al. (2007). Epinephrine-induced activation of LW-mediated sickle cell adhesion and vaso-occlusion in vivo. Blood 110, 2708-2717. doi: 10.1182/blood-200611-056101

Conflict of Interest: The authors declare that the research was conducted in the absence of any commercial or financial relationships that could be construed as a potential conflict of interest.

Copyright (C) 2020 Bokov, El Jurdi, Denjoy, Peiffer, Medjahdi, Holvoet, Benkerrou and Delclaux. This is an open-access article distributed under the terms of the Creative Commons Attribution License (CC BY). The use, distribution or reproduction in other forums is permitted, provided the original author(s) and the copyright owner(s) are credited and that the original publication in this journal is cited, in accordance with accepted academic practice. No use, distribution or reproduction is permitted which does not comply with these terms. 


\section{APPENDIX}

TABLE A1 | Static lung volumes and lung diffusion of the 89 enrolled children.

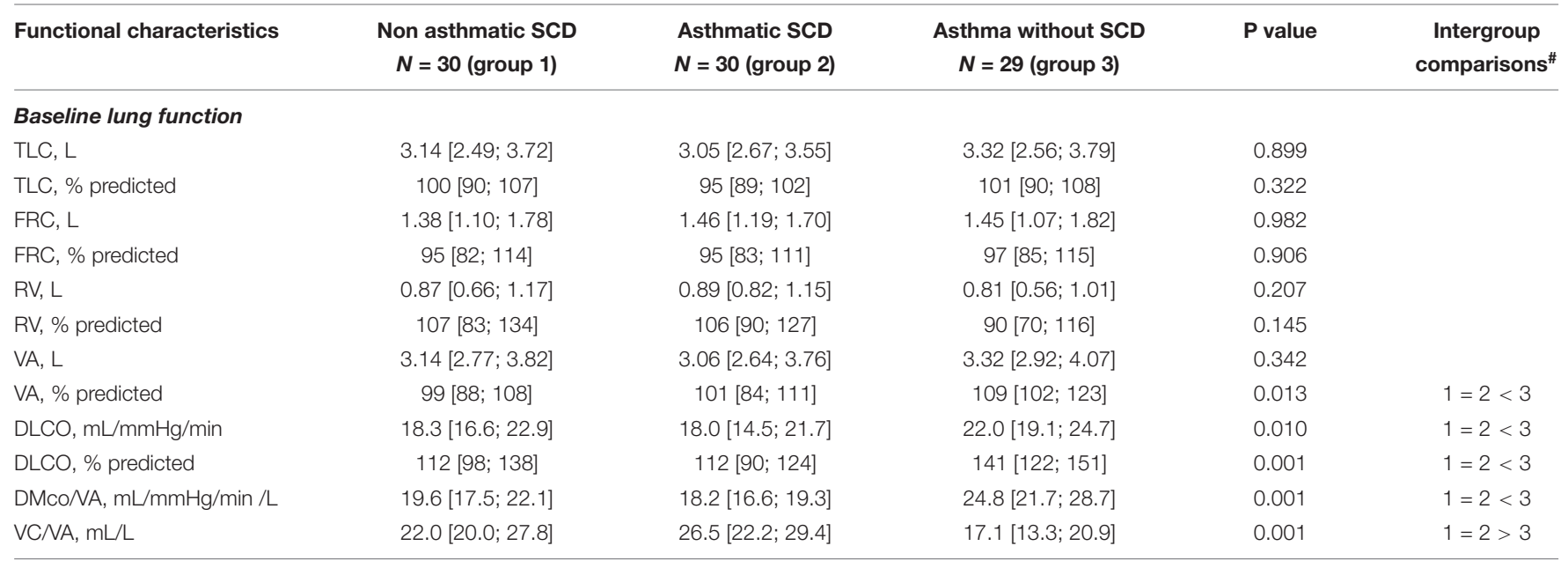

VA denotes alveolar volume. "Post hoc two-group comparisons were performed using the Mann-Whitney $U$ test or the chi-square test, as appropriate (see section "Materials and Methods"). 